\title{
The performance of anthropometric measures to predict diabetes mellitus and hypertension among adults in Jordan
}

\author{
Yousef Khader $^{1 *} \mathbb{D}$, Anwar Batieha', Hashem Jaddou', Mohammed El-Khateeb² and Kamel Ajlouni ${ }^{2}$
}

\begin{abstract}
Objectives: This study aimed to evaluate and compare the abilities of waist circumference (WC), body mass index (BMI), hip circumference (HC), waist-to-hip ratio (WHR) and waist-to-height ratio (WHtR) to predict recently and previously diagnosed diabetes and hypertension and assess their appropriate cut-off values among Jordanian adults.

Methods: Data from the 2017 cardiovascular risk factors survey were analyzed to achieve the study objective. The survey collected extensive data from a national population-based sample of Jordanian residents. A structured questionnaire was used to collect sociodemographic variables and clinical data. Blood samples were taken for biochemical measurements. Anthropometric characteristics were measured by the same team of trained field researchers.

Results: This study included a total of 1193 men and 2863 women. Their age ranged from 18 to 90 year with a mean (SD) of 43.8 (14.2) year. WHtR performed better than other anthropometric measures and had a good ability (AUC > 0.80) among women and fair ability among men to predict newly diagnosed diabetes and previously diagnosed diabetes and hypertension. The appropriate cut-off points for anthropometric measures among women were $92 \mathrm{~cm}$ form WC, $104 \mathrm{~cm}$ for HC, $30 \mathrm{Kg} / \mathrm{m}^{2}$ for BMl, 0.85 for WHR, and 0.60 for WHtR. For men, the appropriate cut-off points were $100 \mathrm{~cm}$ for WC, $104 \mathrm{~cm}$ for HC, $27 \mathrm{Kg} / \mathrm{m}^{2}$ for BMI, 0.93 for WHR, and 0.57 for WHtR.

Conclusion: WHtR performed better than other anthropometric measures in predicting diabetes and hypertension among adult population in Jordan. We recommend WHtR as a measure of choice with a cut-off value of 0.6 for women and 0.57 for men to predict diabetes and hypertension among Jordanians.
\end{abstract}

Keywords: Anthropometric measures, Diabetes mellitus, Hypertension, Receiver operating characteristics

\section{Introduction}

The global burden of non-communicable diseases (NCDs) is immense and increasing. NCDs accounted for $70 \%$ of the estimated 56.4 million deaths worldwide in 2015 , with almost $80 \%$ of these deaths are occurring in low- and middle-income countries [1]. In the Eastern Mediterranean Region (EMR), 57\% of deaths in the region are attributed to NCDs [2]. Unhealthy diets, physical inactivity, and obesity are the main underlying risk factors of NCDs in the EMR [3]. In Jordan, the overall

\footnotetext{
* Correspondence: yskhader@just.edu.jo

${ }^{1}$ Department of Public Health, Jordan University of Science and Technology, P.O.Box 3030, Irbid 22110, Jordan

Full list of author information is available at the end of the article
}

age-standardized prevalence rate of diabetes increased from $13.0 \%$ in 1994 to $23.7 \%$ in 2017 [4]. In 2017, the age-standardized prevalence of hypertension in Jordan was $33.8 \%$ among men and $29.4 \%$ among women [5].

Central obesity is a common cardiometabolic risk factor. Anthropometric measures including waist circumference (WC), body mass index (BMI), hip circumference (HC), waist-to-hip ratio (WHR) and waist-to-height ratio (WHtR) have been commonly used to predict the risk of diabetes and hypertension. BMI and WC are the most commonly used anthropometric measures for prediction of cardiometabolic risk factors [6]. However, BMI does not provide information on body fat distribution and WC does not take into account intraindividual and ethnic 
differences in lean body mass, body shape and height [6]. WHtR demonstrated higher ability than other anthropometric measures in predicting cardiometabolic abnormalities by taking into account both central fat deposition and intraindividual differences in height [7].

Considerable controversy still exists as to which measure most accurately defines body fat distribution. Studies from different countries and ethnicities in the world showed that anthropometric measures have different predictive powers for diabetes and hypertension [8-24]. Therefore, the predictive power of anthropometric measures and their appropriate cut-off points should be established for different ethnicities. This study aimed to evaluate and compare the abilities of WC, BMI, WHR, $\mathrm{HC}$ and WHtR to predict recently and previously diagnosed diabetes and hypertension and assess their appropriate cut-off values among Jordanian adults.

\section{Methods}

\section{Study design and sampling}

A multipurpose national household survey was conducted among Jordanian adults over a period of four months in the year 2017. The detailed study design, methods, and procedures were described in previous publications $[4,5]$. In brief, a multistage sampling technique was used to select a nationally representative sample from the population of Jordan. A village/city was selected from each of the 12 governorates of Jordan. The study procedures took place in the main health center in the selected villages/cities. The research team visited the households in the catchment area of the health center to invite adults to report to the center fasting in a given day after explaining the study for them. Subjects were asked not to take their medications in that day and to bring the medications with them to the health center. Subjects aged $\geq 18$ years were eligible for inclusion in the study.

\section{Data collection}

Data were collected using a structured validated and pilot tested questionnaire by trained interviewers. The questionnaire was the same one that has been used in 2009 survey. The questionnaire included questions to assess the sociodemographic variables and clinical characteristics of participants, including self-reported diagnosis and treatment of diabetes and hypertension. Three blood samples were drawn from a cannula inserted into the antecubital vein and used for the different laboratory measurements. Tubes containing sodium fluoride potassium oxalate were used for glucose measurement.

Table 1 The socio-demographic, anthropometric, and clinical characteristics of participants according to gender

\begin{tabular}{|c|c|c|c|c|c|c|}
\hline & \multicolumn{2}{|c|}{$\begin{array}{l}\text { Women } \\
N=2863\end{array}$} & \multicolumn{2}{|c|}{$\begin{array}{l}\text { Men } \\
N=1193\end{array}$} & \multirow{2}{*}{$\begin{array}{l}\text { Total } \\
\mathrm{N}\end{array}$} & \multirow[t]{2}{*}{$P$-value } \\
\hline & $n$ & $\%$ & $n$ & $\%$ & & \\
\hline Age (year) & & & & & & $<0.001$ \\
\hline$<50$ & 1966 & 68.8 & 648 & 54.4 & 2614 & \\
\hline$\geq 50$ & 890 & 31.2 & 543 & 45.6 & 1433 & \\
\hline Marital status & & & & & & $<0.001$ \\
\hline Single & 462 & 16.1 & 144 & 12.1 & 606 & \\
\hline Married & 2401 & 83.9 & 1049 & 87.9 & 3450 & \\
\hline Region & & & & & & $<0.001$ \\
\hline North & 922 & 32.2 & 390 & 32.7 & 1312 & \\
\hline Middle & 1295 & 45.2 & 471 & 39.5 & 1766 & \\
\hline South & 646 & 22.6 & 332 & 27.8 & 978 & \\
\hline Smoking status & & & & & & $<0.001$ \\
\hline None smoker & 2628 & 91.8 & 592 & 49.6 & 3220 & \\
\hline Past smoker & 46 & 1.6 & 206 & 17.3 & 252 & \\
\hline Current smoker & 189 & 6.6 & 395 & 33.1 & 584 & \\
\hline High triglycerides level & 1036 & 36.2 & 647 & 54.2 & 1683 & $<0.001$ \\
\hline Low HDL & 1659 & 57.9 & 732 & 61.4 & 2391 & $<0.001$ \\
\hline Previously diagnosed diabetes & 433 & 15.1 & 326 & 27.3 & 759 & $<0.001$ \\
\hline Recently diagnosed diabetes & 64 & 2.2 & 44 & 3.7 & 108 & $<0.001$ \\
\hline Previously diagnosed hypertension & 614 & 21.4 & 336 & 28.2 & 950 & $<0.001$ \\
\hline Recently diagnosed hypertension & 529 & 18.5 & 323 & 27.1 & 852 & $<0.001$ \\
\hline
\end{tabular}


Table 2 The mean and the 95\% confidence intervals for the anthropometric characteristics for men and women

\begin{tabular}{|c|c|c|c|c|c|c|c|}
\hline \multirow{3}{*}{$\frac{\text { Anthropometric measures }}{\text { Waist Circumference }(\mathrm{cm})}$} & \multicolumn{3}{|c|}{$\begin{array}{l}\text { Women } \\
N=2827\end{array}$} & \multicolumn{3}{|c|}{$\begin{array}{l}\text { Men } \\
N=1185\end{array}$} & \multirow{3}{*}{$\begin{array}{c}P \text {-value } \\
<0.001\end{array}$} \\
\hline & \multirow{2}{*}{$\frac{\text { Mean }}{92.7}$} & \multicolumn{2}{|c|}{ 95\% Confidence Interval } & \multirow{2}{*}{$\begin{array}{l}\text { Mean } \\
98.9\end{array}$} & \multicolumn{2}{|c|}{ 95\% Confidence Interval } & \\
\hline & & 92.1 & 93.4 & & 98.0 & 99.8 & \\
\hline Hip Circumference (cm) & 108.3 & 107.8 & 108.8 & 104.7 & 104.1 & 105.4 & $<0.001$ \\
\hline Body Mass Index (Kg/m²) & 30.0 & 29.8 & 30.2 & 28.4 & 28.2 & 28.7 & $<0.001$ \\
\hline Waist to Hip Ratio & 0.86 & 0.85 & 0.86 & 0.94 & 0.94 & 0.95 & $<0.001$ \\
\hline Waist to Height Ratio & 0.59 & 0.58 & 0.59 & 0.57 & 0.57 & 0.58 & $<0.001$ \\
\hline
\end{tabular}

\section{(a) Recently diagnosed diabetes}
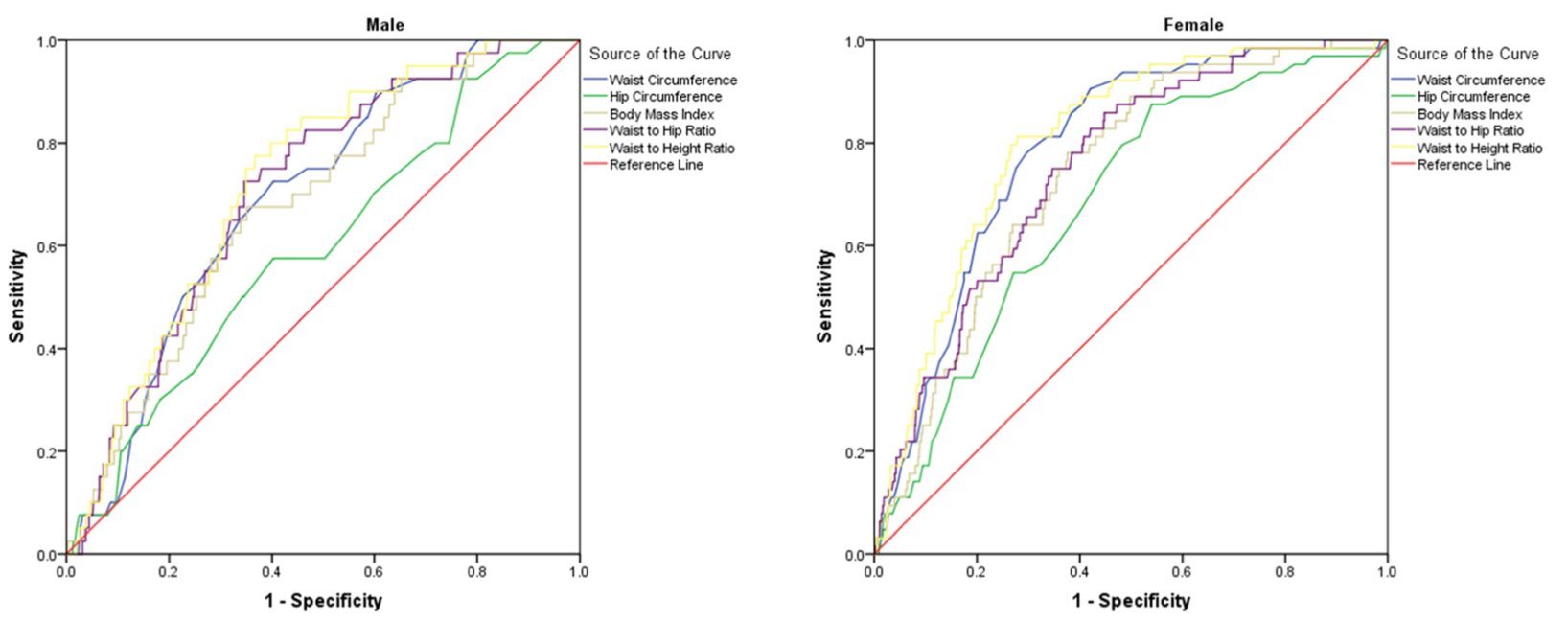

\section{(b) Previously diagnosed diabetes}
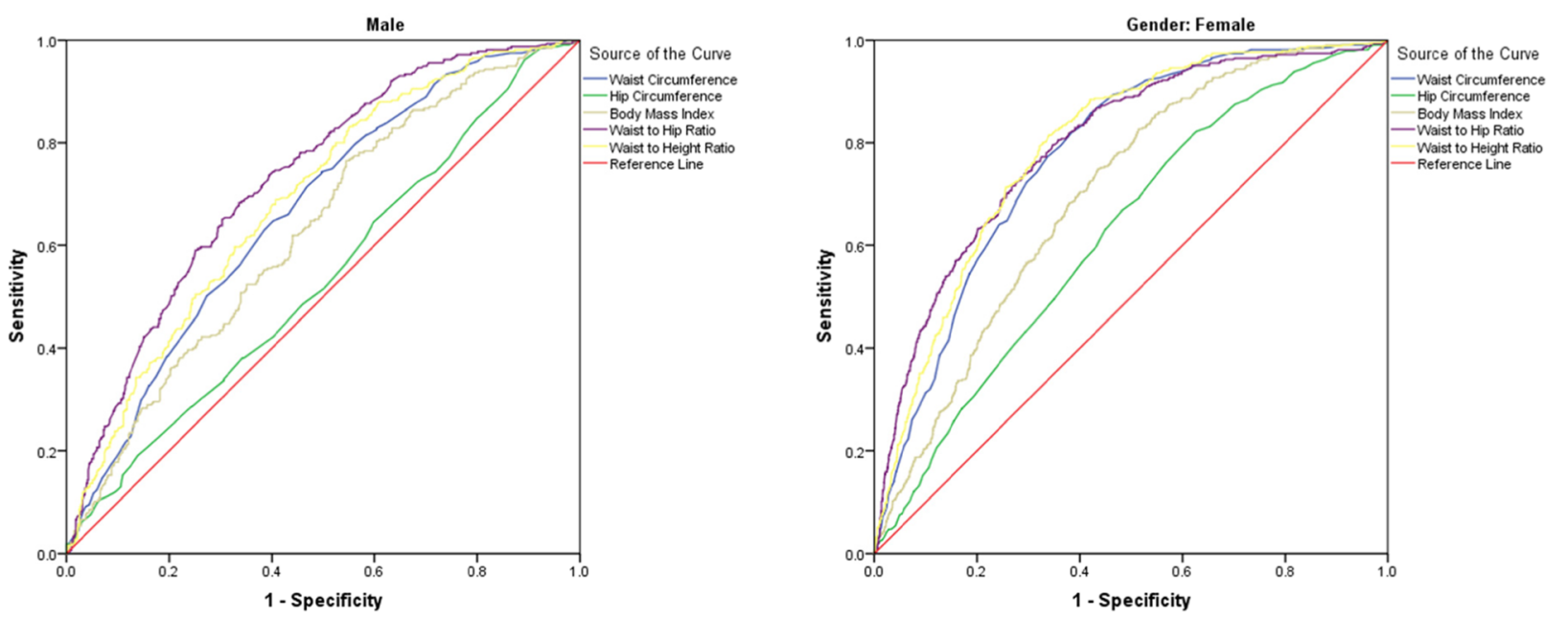

Fig. 1 Receiver operating characteristic curve illustrating the ability of anthropometric measures to predict $\mathbf{a}$ recently diagnosed diabetes and $\mathbf{b}$ previously diagnosed diabetes according to gender 
Samples were centrifuged within $1 \mathrm{~h}$ at the survey site, and transferred by separate labeled tubes in ice boxes to the central laboratory of the National Center of Diabetes, Endocrinology, and Genetics in Amman, Jordan. All biochemical measurements were carried out by the same team of laboratory technicians using the same method throughout the study period. Fasting plasma glucose was measured by the glucose oxidase method, using a Cobas Analyzer (Roche).

\section{Anthropometric measurements}

Single measurement was taken for each anthropometric measures. Weight was measured, while subjects minimally clothed without shoes using digital scales (seca).
Height was measured using a portable stadiometer (SECA 214 portable stadiometer). BMI was calculated as weight in kilograms divided by height in meters squared. WC was measured at the midway between iliac crest and lower rib margin, over light clothing, using unstretchable tape (seca 203), without any pressure to body surface. WHR was calculated as WC divided by hip circumference and WHtR as WC divided by height in centimeter. Measurements were taken by the same team of well-trained persons using the same tools.

\section{Variable definitions}

Recently diagnosed diabetes was defined as having fasting blood sugar $\geq 126 \mathrm{mg} / \mathrm{dl}(\geq 7.0 \mathrm{mmol} / \mathrm{l})$ at the time of

\section{(a) Recently diagnosed hypertension}
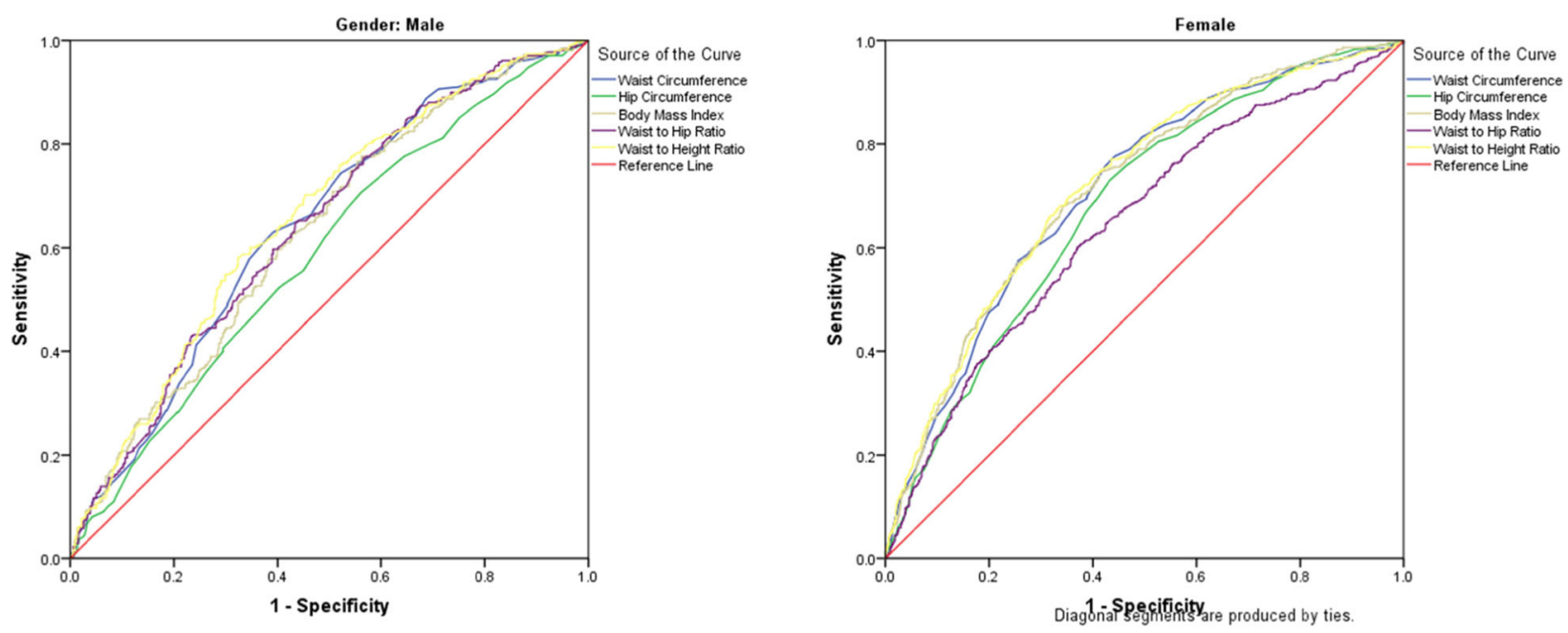

(b) Previously diagnosed hypertension
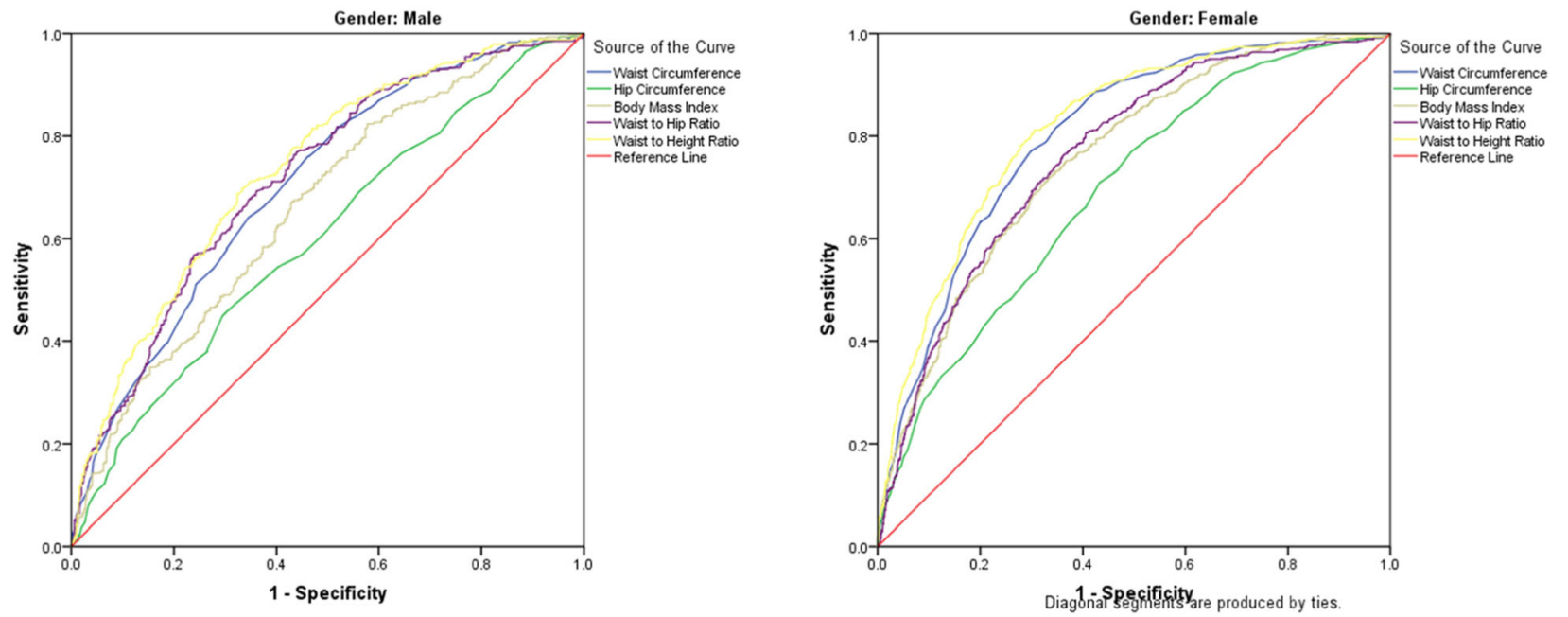

Fig. 2 Receiver operating characteristic curve illustrating the ability of anthropometric measures to predict a recently diagnosed hypertension and $\mathbf{b}$ previously diagnosed hypertension according to gender 
the survey with no prior history of diabetes. Recently diagnosed hypertension was defined as having a blood pressure $\geq 140 \mathrm{mmHg}$ systolic and/ or $90 \mathrm{mmHg}$ diastolic at the time of the survey, with no prior history of hypertension. Previously diagnosis of diabetes and hypertension were self-reported by participants.

\section{Statistical analysis}

Data were entered and analyzed using the IBM SPSS, version 20. Data were described using means and percentages. Percentages were compared using chi-square test and difference between means were tested using independent $t$ test. The performance of anthropometric measures was evaluated using receiver operating characteristics (ROC) analyses for each gender [25]. Validity of the test was assessed by calculating area under curve (AUC). The AUC values were classified as: $0.5-0.6$ fail, 0.6-0.7 poor, 0.7-0.8 fair, 0.8-0.9 good and 0.9-1.0 excellent [26]. Appropriate cut-off values were defined based on Youden's J statistic (maximum [sensitivity + specificity - 1]). To further judge the ability of anthropometric measures to predict previously and recently diagnosed diabetes and hypertension, anthropometric measures were dichotomized based on the established cut-off values in this study and tested for their associations using binary logistic regression after adjusting for age effect. All regression analyses were stratified by gender.

We did not adjust for multiple comparisons in analysis because almost all $p$-values were almost close to 0 . A $p$ value $<0.05$ was considered statistically significant.

\section{Results}

\section{Participants' characteristics}

This study included a total of 1193 men and 2863 women. Their aged ranged from 18 to 90 years with a mean (SD) of 43.8 (14.2) year. About $27.3 \%$ of men and $15.1 \%$ of women were previously diagnosed with diabetes, $3.7 \%$ of men and $2.2 \%$ of women were recently diagnosed with diabetes, $28.2 \%$ of men and $21.4 \%$ of

Table 3 Area under receiver operating characteristic curve illustrating the ability of anthropometric measures to predict recently and previously diagnosed diabetes and hypertension according to gender

\begin{tabular}{|c|c|c|c|c|c|c|}
\hline \multirow{3}{*}{ Recently diagnosed diabete } & \multicolumn{3}{|c|}{ Women } & \multicolumn{3}{|l|}{ Men } \\
\hline & \multirow[t]{2}{*}{$\mathrm{AUC}$} & \multicolumn{2}{|c|}{ 95\% confidence interval } & \multirow[t]{2}{*}{ AUC } & \multicolumn{2}{|c|}{ 95\% confidence interval } \\
\hline & & & & & & \\
\hline Waist Circumference & 0.80 & 0.74 & 0.83 & 0.70 & 0.62 & 0.76 \\
\hline Hip Circumference & 0.68 & 0.62 & 0.74 & 0.60 & 0.51 & 0.68 \\
\hline Body Mass Index & 0.74 & 0.69 & 0.79 & 0.68 & 0.60 & 0.76 \\
\hline Waist to Hip Ratio & 0.75 & 0.70 & 0.80 & 0.69 & 0.64 & 0.78 \\
\hline Waist to Height Ratio & 0.81 & 0.76 & 0.85 & 0.72 & 0.66 & 0.79 \\
\hline \multicolumn{7}{|c|}{ Previously diagnosed diabetes } \\
\hline Waist Circumference & 0.78 & 0.75 & 0.76 & 0.67 & 0.63 & 0.65 \\
\hline Hip Circumference & 0.62 & 0.59 & 0.61 & 0.54 & 0.50 & 0.52 \\
\hline Body Mass Index & 0.70 & 0.67 & 0.69 & 0.63 & 0.59 & 0.61 \\
\hline Waist to Hip Ratio & 0.80 & 0.77 & 0.78 & 0.69 & 0.65 & 0.67 \\
\hline Waist to Height Ratio & 0.81 & 0.77 & 0.78 & 0.73 & 0.70 & 0.71 \\
\hline \multicolumn{7}{|c|}{ Recently diagnosed hypertension } \\
\hline Waist Circumference & 0.71 & 0.69 & 0.74 & 0.64 & 0.60 & 0.68 \\
\hline Hip Circumference & 0.68 & 0.66 & 0.71 & 0.59 & 0.55 & 0.63 \\
\hline Body Mass Index & 0.71 & 0.69 & 0.74 & 0.63 & 0.59 & 0.67 \\
\hline Waist to Hip Ratio & 0.71 & 0.69 & 0.74 & 0.64 & 0.60 & 0.68 \\
\hline Waist to Height Ratio & 0.72 & 0.69 & 0.74 & 0.66 & 0.62 & 0.69 \\
\hline \multicolumn{7}{|c|}{ Previously diagnosed hypertension } \\
\hline Waist Circumference & 0.80 & 0.78 & 0.82 & 0.70 & 0.67 & 0.74 \\
\hline Hip Circumference & 0.69 & 0.67 & 0.72 & 0.60 & 0.56 & 0.64 \\
\hline Body Mass Index & 0.76 & 0.74 & 0.78 & 0.66 & 0.62 & 0.70 \\
\hline Waist to Hip Ratio & 0.76 & 0.74 & 0.78 & 0.96 & 0.68 & 0.75 \\
\hline Waist to Height Ratio & 0.82 & 0.80 & 0.83 & 0.73 & 0.70 & 0.77 \\
\hline
\end{tabular}


women were previously diagnosed with hypertension and $27.1 \%$ of men and $18.5 \%$ of women were recently diagnosed with hypertension. Table 1 shows the sociodemographic, anthropometric, and clinical characteristics of participants according to gender.

Table 2 shows the means and the 95\% confidence intervals for the anthropometric characteristics for men and women. Women had significantly higher means of BMI, HC and WHtR and lower means of WC and WHR than men.

ROC analysis (Figs. 1 and 2) showed that all anthropometric measures had better performance to predict recently and previously diagnosed diabetes and hypertension among women than that among men. Table 3 shows the area under the ROC curve for men and women. Among women, WHtR performed better than other anthropometric measures and had a good accuracy $($ AUC $>0.80)$ to predict incident and prevalent cases of diabetes and prevalent cases of hypertension. It had fair accuracy to predict incident cases of hypertension. Among men, WHtR had fair accuracy and performed better than other anthropometric measures to predict recently and previously diagnosed diabetes and previously diagnosed hypertension. Moreover, WC had a good accuracy to predict recently diagnosed diabetes and previously diagnosed hypertension among women and fair accuracy to predict recently diagnosed diabetes and previously diagnosed hypertension among men. BMI and WHR had fair accuracy and HC had poor accuracy to predict the studied outcomes among women and had poor performance to predict the studied outcomes in men.

Youden's J statistic was used to capture the performance of anthropometric measures and define appropriate cut-off values. The appropriate cut-off points for anthropometric measures among women were $92 \mathrm{~cm}$ for

Table 4 Appropriate anthropometric measures cut-off values for predicting previously and recently diagnosed diabetes and hypertension and their values of sensitivity and specificity

\begin{tabular}{|c|c|c|c|c|c|c|}
\hline & \multicolumn{3}{|l|}{ Women } & \multicolumn{3}{|l|}{ Men } \\
\hline & Cut-off value & Sensitivity & Specificity & Cut-off value & Sensitivity & Specificity \\
\hline \multicolumn{7}{|l|}{ Waist Circumference } \\
\hline Recently diagnosed diabetes & 92.0 & $81 \%$ & $66 \%$ & 100.0 & $65 \%$ & $66 \%$ \\
\hline Previously diagnosed diabetes & 92.0 & $82 \%$ & $62 \%$ & 100.0 & $71 \%$ & $53 \%$ \\
\hline Recently diagnosed hypertension & 90.0 & $76 \%$ & $58 \%$ & 100.0 & & \\
\hline Previously diagnosed hypertension & 92.0 & $82 \%$ & $65 \%$ & 100.0 & $64 \%$ & $65 \%$ \\
\hline \multicolumn{7}{|l|}{ Hip Circumference } \\
\hline Recently diagnosed diabetes & 104.0 & $88 \%$ & $46 \%$ & 104.0 & $58 \%$ & $60 \%$ \\
\hline Previously diagnosed diabetes & 100.0 & $82 \%$ & $37 \%$ & 100.0 & $94 \%$ & $55 \%$ \\
\hline Recently diagnosed hypertension & 104.0 & $73 \%$ & $57 \%$ & 104.0 & $54 \%$ & $60 \%$ \\
\hline Previously diagnosed hypertension & 104.0 & $77 \%$ & $51 \%$ & 102.0 & $62 \%$ & $51 \%$ \\
\hline \multicolumn{7}{|l|}{ Body Mass Index } \\
\hline Recently diagnosed diabetes & 30.0 & $56 \%$ & $77 \%$ & 27.0 & $63 \%$ & $68 \%$ \\
\hline Previously diagnosed diabetes & 28.0 & $77 \%$ & $54 \%$ & 27.0 & $77 \%$ & $50 \%$ \\
\hline Recently diagnosed hypertension & 30.0 & $68 \%$ & $66 \%$ & 27.0 & $77 \%$ & $50 \%$ \\
\hline Previously diagnosed hypertension & 30.0 & $72 \%$ & $67 \%$ & 27.0 & $82 \%$ & $50 \%$ \\
\hline \multicolumn{7}{|l|}{ Waist to Hip Ratio } \\
\hline Recently diagnosed diabetes & 0.85 & $75 \%$ & $65 \%$ & 0.93 & $75 \%$ & $65 \%$ \\
\hline Previously diagnosed diabetes & 0.85 & $76 \%$ & $68 \%$ & 0.93 & $65 \%$ & $69 \%$ \\
\hline Recently diagnosed hypertension & 0.85 & $61 \%$ & $62 \%$ & 0.93 & $64 \%$ & $57 \%$ \\
\hline Previously diagnosed hypertension & 0.85 & $72 \%$ & $68 \%$ & 0.93 & $69 \%$ & $64 \%$ \\
\hline \multicolumn{7}{|l|}{ Waist to Height Ratio } \\
\hline Recently diagnosed diabetes & 0.60 & $84 \%$ & $64 \%$ & 0.57 & $80 \%$ & $73 \%$ \\
\hline Previously diagnosed diabetes & 0.60 & $83 \%$ & $63 \%$ & 0.57 & $68 \%$ & $60 \%$ \\
\hline Recently diagnosed hypertension & 0.60 & $71 \%$ & $63 \%$ & 0.57 & $70 \%$ & $67 \%$ \\
\hline Previously diagnosed hypertension & 0.60 & $81 \%$ & $69 \%$ & 0.57 & $71 \%$ & $65 \%$ \\
\hline
\end{tabular}


WC, $104 \mathrm{~cm}$ for $\mathrm{HC}, 30 \mathrm{Kg} / \mathrm{m}^{2}$ for BMI, 0.85 for WHR, and 0.60 for WHtR. For men, the appropriate cut-off points were $100 \mathrm{~cm}$ for WC, $104 \mathrm{~cm}$ for $\mathrm{HC}, 27 \mathrm{Kg} / \mathrm{m}^{2}$ for BMI, 0.93 for WHR, and 0.57 for WHtR (Table 4).

All anthropometric measures were dichotomized using the established cut-off values and tested for their associations with the studied outcomes after adjusting for age effect (Table 5). All dichotomized measures were significantly associated with increased odds of recently and previously diagnosed diabetes and hypertension, except $\mathrm{HC}$ that did not show significant association with recently and previously diagnosed diabetes. Among women, $W C>92 \mathrm{~cm}$ and WHtR $>0.60$ were significantly associated with almost 3 to 5 times increased odds of recently and previously diagnosed diabetes and hypertension. Among men, $W C>100 \mathrm{~cm}$ and WHtR $>0.57$ were significantly associated with almost 2 to 4 times increased odds of recently and previously diagnosed diabetes and hypertension.

\section{Discussion}

The findings of previous studies that compared the predictive power of anthropometric measures to predict cardiometabolic conditions are contradicting. Our study demonstrated a higher ability for WHtR to predict diabetes and hypertension among Jordanian adult men and women compared to other measures. This finding is consistent with the findings of other studies that showed WHtR a better predictor compared to other measures among women [8-10] and men [11] of different populations including a meta-analysis [12] of ten studies and a systematic review of 13 studies which demonstrated superiority of WHtR over other measures [13]. WHtR has been argued to be superior to a single measure of WC by taking into account intraindividual and ethnic differences in height [6]. However, there was a lot of inconsistency regarding the different anthropometric measures in predicting diabetes and hypertension. WHR was reported to be a better predictor in a number of countries [14-17]. Also, WC was reported to show

Table 5 Age-adjusted associations between anthropometric measures that were dichotomized based on the established cut-off values and previously and recently diagnosed diabetes and hypertension

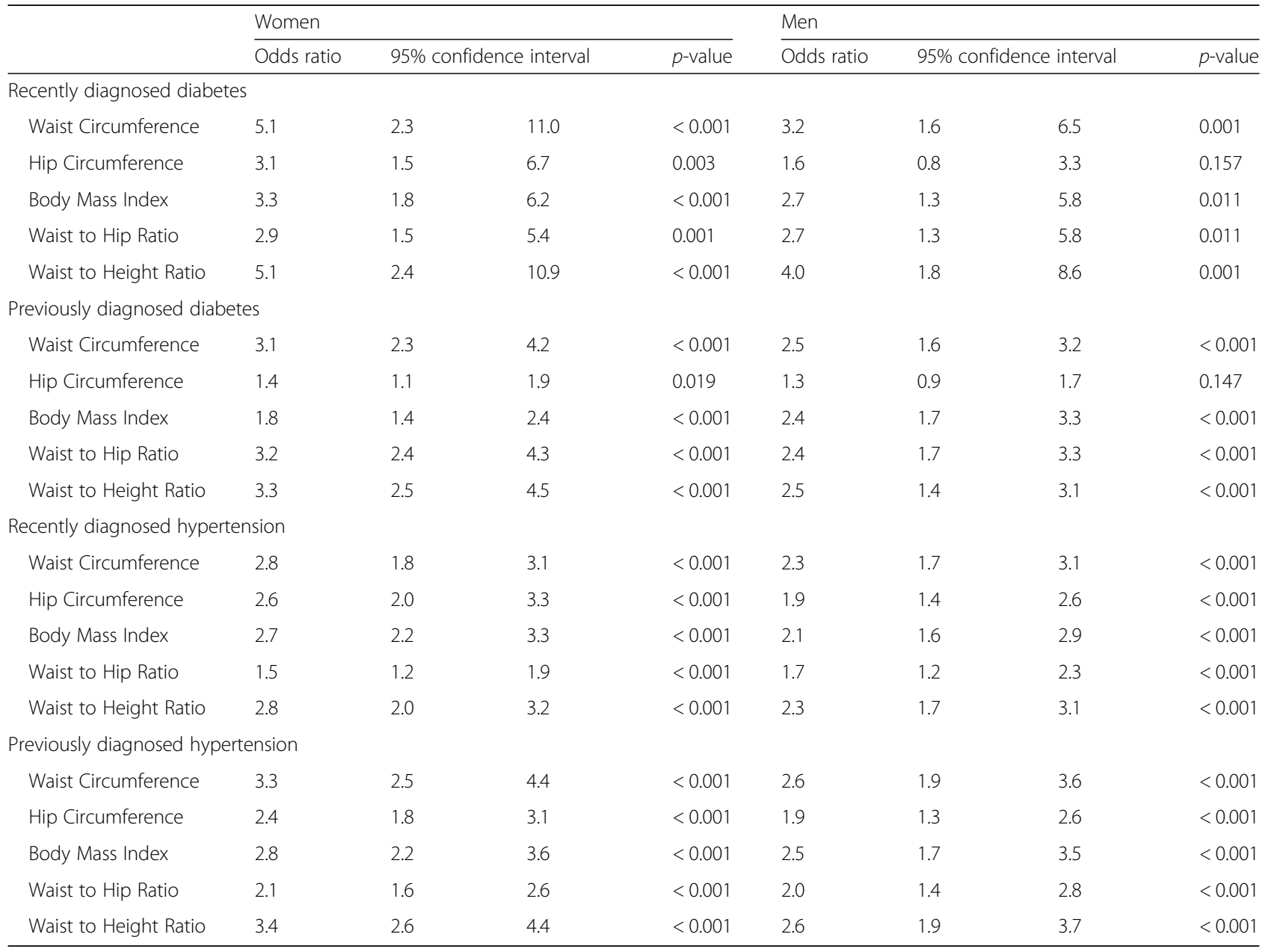


superiority over other anthropometric measures in the prediction of type 2 diabetes in British women [18], U.S. men [19], German women [11], and Indian men and women [20].

Regarding BMI, systematic reviews [6, 21] encompassing Asian and Caucasian populations have consistently reported the inferior utility of BMI in identifying undiagnosed diabetes as compared with abdominal indices.

On the other hand, other studies demonstrated that BMI, WHR, WC, and WHtR had similar predictive powers for the risk of type 2 diabetes [24]. WHR, WC, and WHTR performed similarly well in Bangladeshi women [23]. A meta-analysis of 32 studies [24] showed that BMI, WHR, and WC had similar associations with incident diabetes.

Possible reasons for variation between studies might be due to ethnic and racial differences and differences in body composition and fat distribution between different ethnic groups, genders and age groups. Other reasons might include different study designs, different WC measurement protocols or different methods for defining cardiometabolic outcomes.

The appropriate cut-off points for predicting diabetes and hypertension among Jordanian women were $92 \mathrm{~cm}$ form WC, $104 \mathrm{~cm}$ for $\mathrm{HC}, 30 \mathrm{Kg} / \mathrm{m}^{2}$ for BMI, 0.85 for WHR, and 0.60 for WHtR. For men, the appropriate cut-off points were $100 \mathrm{~cm}$ for WC, $104 \mathrm{~cm}$ for $\mathrm{HC}, 27$ $\mathrm{Kg} / \mathrm{m} 2$ for BMI, 0.93 for WHR, and 0.57 for WHtR. Different cut-off values were reported for other populations. Ethnic and racial differences might explain the discrepancy in cut-off values between different studies.

The findings of ROC analysis in this study are supported by findings of the age-adjusted associations of dichotomized anthropometric measures with the outcome variables. WHtR and WC, using the established cut-off values, had strong association with previously and recently diagnosed diabetes and hypertension.

Our study had several strengths including a large national sample. In addition, the anthropometric measures were performed by the same team of field researchers. The main limitation of this study is the lower response rate $(40 \%)$ in males. This is expected given that the employment rate in men in Jordan is much higher than that in women. An important limitation to consider when interpreting the findings is the possibility of measurement error (e.g. we measured the WC over light clothing). Another limitation is that the predictive ability of these anthropometric measures is correlated or associated with cardiovascular disease risk factors but not with cardiovascular disease events itself. So further studies are needed to correlate these measures with actual events.

\section{Conclusions}

WHtR performed the best in predicting diabetes and hypertension among adult population in Jordan. We recommend WHtR as a measure of choice with a cut-off value of 0.6 for women and 0.57 for men to predict diabetes and hypertension among Jordanians. Moreover, we recommend that WHtR should be measured routinely in health system and used as one of the indicators for the risk assessment of diabetes and hypertension.

\section{Abbreviations \\ AUC: Area under curve; BMI: Body mass index; EMR: Eastern Mediterranean Region; HC: Hip circumference; NCDs: Non-communicable diseases; ROC: Receiver operating characteristics; WC: Waist circumference; WHR: Waist-to-hip ratio; WHtR: Waist-to-height ratio}

\section{Acknowledgements}

Not applicable.

\section{Authors' contributions}

ME and KA conducted the laboratory analysis. YK, AB, AJ supervised the data collection and analyzed the data. All authors wrote, read and approved the final manuscript.

\section{Funding}

The study is funded by the Research Fund at Jordan Ministry of Higher Education. The funding body has no role in the design of the study and collection, analysis, and interpretation of data and in writing the manuscript.

\section{Availability of data and materials}

The datasets used and/or analysed during the current study are available from the corresponding author on reasonable request.

\section{Ethics approval and consent to participate}

Ethical approval was obtained from the Institutional Review Board at the National Center for Diabetes, Endocrinology, and Genetics. All participants signed the informed consent.

\section{Consent for publication}

Not applicable.

\section{Competing interests}

The authors declare that they have no competing interests.

\section{Author details}

'Department of Public Health, Jordan University of Science and Technology, P.O.Box 3030, Irbid 22110, Jordan. ${ }^{2}$ The National Center for Diabetes,

Endocrinology and Genetics, The Jordan University, Amman, Jordan.

Received: 4 August 2019 Accepted: 17 October 2019

\section{References}

1. World Health Organization. 2015. NCD mortality and morbidity, Global Health Observatory (GHO) data. Available at: http://www.who.int/gho/ncd/ mortality_morbidity/en/ [Accessed 1 July, 2019].

2. World Health Organization. Regional Office of the Eastern Mediterranean: Non-Communicable diseases 2016. Available at: http://www.emro.who.int/ entity/ncds/index.html [Accessed 1 July, 2019].

3. Rahim HF, Sibai A, Khader Y, Hwalla N, Fadhil I, Alsiyabi H, Mataria A, Mendis S, Mokdad AH, Husseini A. Non-communicable diseases in the Arab world. Lancet. 2014;383(9914):356-67.

4. Ajlouni K, Batieha A, Jaddou H, Khader Y, Abdo N, El-Khateeb M, Hyassat D, Al-Louzi D. Time trends in diabetes mellitus in Jordan between 1994 and 2017. Diabet Med. 2019. https://doi.org/10.1111/dme.13894.

5. Khader Y, Batieha A, Jaddou H, Rawashdeh SI, El-Khateeb M, Hyassat D, Khader A, Ajlouni K. Hypertension in Jordan: prevalence, awareness, control, and its associated factors. Int J Hypertens. 2019;2019:3210617.

6. Ashwell M, Gunn P, Gibson S. Waist-to-height ratio is a better screening tool than waist circumference and BMI for adult cardiometabolic risk factors: systematic review and meta-analysis. Obes Rev. 2012;13:275-86. 
7. Ashwell M, Gibson S. Waist-to-height ratio as an indicator of 'early health risk': simpler and more predictive than using a 'matrix' based on BMI and waist circumference. BMJ Open. 2016;6:e010159.

8. Lin WY, Lee LT, Chen CY, Lo H, Hsia HH, Liu IL, Lin RS, Shau WY, Huang KC Optimal cut-off values for obesity:using simple anthropometric indices to predict cardiovascular risk factors in Taiwan. Int J Obes Relat Metab Disord. 2002;26(9):1232-8.

9. Zhang ZQ, Deng J, He LP, Ling WH, Su YX, Chen YM. Comparison of various anthropometric and body fat indices in identifying cardiometabolic disturbances in Chinese men and women. PLoS One. 2013;8:e70893.

10. Pua YH, Ong PH. Anthropometric indices as screening tools for cardiovascular risk factors in Singaporean women. Asia Pac J Clin Nutr. 2005; 14(1):74-9.

11. Schulze MB, Heidemann C, Schienkiewitz A, Bergmann MM, Hoffmann K, Boeing $\mathrm{H}$. Comparison of anthropometric characteristics in predicting the incidence of type 2 diabetes in the EPIC-Potsdam study. Diabetes Care. 2006;29(8):1921-3.

12. Lee CM, Huxley RR, Wildman RP, Woodward M. Indices of abdominal obesity are better discriminators of cardiovascular risk factors than BMI: a meta-analysis. J Clin Epidemiol. 2008;61(7):646-53.

13. Corrêa MM, Thumé E, De Oliveira ER, Tomasi E. Performance of the waist-toheight ratio in identifying obesity and predicting non-communicable diseases in the elderly population: A systematic literature review. Arch Gerontol Geriatr. 2016;65:174-82.

14. Esmaillzadeh A, Mirmiran P, Azizi F. Waist-to-hip ratio is a better screening measure for cardiovascular riskfactors than other anthropometric indicators in Tehranian adult men. Int J Obes Relat Metab Disord. 2004;28(10):1325-32.

15. Mirmiran P, Esmaillzadeh A, Azizi F. Detection of cardiovascular risk factors by anthropometric measures in Tehranian adults: receiver operating characteristic (ROC) curve analysis. Eur J Clin Nutr. 2004;58(8):1110-8.

16. Ta MT, Nguyen KT, Nguyen ND, Campbell LV, Nguyen TV. Identification of undiagnosed type 2 diabetes by systolic blood pressure and waist-to-hip ratio. Diabetologia. 2010;53(10):2139-46.

17. Mansour AA, Al-Jazairi MI. Cut off values for anthropometric variables that confer increased risk of type 2 diabetes mellitus and hypertension in Iraq. Arch Med Res. 2007;38(2):253-8.

18. Taylor AE, Ebrahim S, Ben-Shlomo Y, Martin RM, Whincup PH, Yarnell JW, Wannamethee SG, Lawlor DA. Comparison of the associations of body mass index and measures of central adiposity and fat mass with coronary heart disease, diabetes, and all-cause mortality: a study using data from 4 UK cohorts. Am J Clin Nutr. 2010;91(3):547-56.

19. Wang H, Liu A, Zhao T, Gong X, Pang T, Zhou Y, Xiao Y, Yan Y, Fan C, Teng W, Lai Y, Shan Z. Comparison of anthropometric indices for predicting the risk of metabolic syndrome and its components in Chinese adults: a prospective, longitudinal study. BMJ Open. 2017;7(9):e016062.

20. Mamtani MR, Kulkarni HR. Predictive performance of anthropometric indexes of central obesity for the risk of type 2 diabetes. Arch Med Res. 2005:36(5):581-9.

21. Browning LM, Hsieh SD, Ashwell M. A systematic review of waist-to-height ratio as a screening tool for the prediction of cardiovascular disease and diabetes: 0.5 could be a suitable global boundary value. Nutr Res Rev. 2010; 23:247-69.

22. Sargeant LA, Bennett Fl, Forrester TE, Cooper RS, Wilks RJ. Predicting incident diabetes in Jamaica: the role of anthropometry. Obes Res. 2002; 10(8):792-8.

23. Bhowmik B, Munir SB, Diep LM, et al. Anthropometric indicators of obesity for identifying cardiometabolic risk factors in a rural Bangladeshi population. J Diabetes Invest. 2013;4:361-8.

24. Vazquez G, Duval S, Jacobs DR Jr, Silventoinen K. Comparison of body mass index, waist circumference, and waist/hip ratio in predicting incident diabetes: a meta-analysis. Epidemiol Rev. 2007;29:115-28.

25. Swets JA. Measuring the accuracy of diagnostic systems. Science. 1988;240: 1285-93.

26. DeLong ER, DeLong DM, Clarke-Pearson DL. Comparing the areas under two or more correlated receiver operating characteristic curves: a nonparametric approach. Biometrics. 1988;44:837-45.

\section{Publisher's Note}

Springer Nature remains neutral with regard to jurisdictional claims in published maps and institutional affiliations.

\section{Ready to submit your research? Choose BMC and benefit from:}

- fast, convenient online submission

- thorough peer review by experienced researchers in your field

- rapid publication on acceptance

- support for research data, including large and complex data types

- gold Open Access which fosters wider collaboration and increased citations

- maximum visibility for your research: over $100 \mathrm{M}$ website views per year

At BMC, research is always in progress.

Learn more biomedcentral.com/submissions 